\title{
Chronic Maxillary Sinusitis Associated with External Sinus Lift: Report of a Case
}

\author{
Konstantinos Saridakis ${ }^{1 *}$ and Thomas Ziebart ${ }^{2}$ \\ ${ }^{1}$ Department of Oral \& Maxillofacial Surgery, University Hospital of Mainz, Germany \\ ${ }^{2}$ Department of Oral \& Maxillofacial Surgery, University Hospital of Marburg, Germany
}

Submission: February 23, 2017; Published: March 09, 2017

*Corresponding author: Konstantinos Saridakis, University Hospital of Mainz-Department of Oral \& Maxillofacial Surgery, Augustusplatz 2 , Building 901, Mainz 55 131, Germany, Europe, Tel: 004917636871 850; Email: Konstantin.Saridakis@unimedizin-mainz.de

\begin{abstract}
Sinus lift procedures are very commonly used in implantology. One of the major associated with this procedure complication is that of development of maxillary sinusitis. In our case report we presented a patient with chronic sinusitis after external sinus lift and multiple dental implantations in the right maxilla. Subsequently we analyzed through the preoperative diagnostics our treatment plan and its outcome. Alternative therapies were mentioned according to the literature.
\end{abstract}

Keywords: External sinus lift; Implantation; Periimplantitis; Sinusitis; Naso-antral window

\section{Introduction}

Sinus floor elevation is one of the most popular procedures in the treatment of severely resorbed maxilla before insertion of dental implants after its first report over 30 years ago [1-3]. Since the first described Technique with an external osteotomy in the anterior wall of the sinus by Boyne, subsequent developments of the technique were performed. It is supposed to be a highly predictable method with more than $95 \%$ success rates $[4,5]$. In addition, the technique is considered to be safe, has no special technical difficulties and can be performed as well under local anesthesia. The procedure can be subdivided into various categories according to the performed technique, the type of the used graft and the time of the implant placement.

Nonetheless, like any surgical procedure, it is not without risks. Complications can cause moderate till severe problems, which involve revision of the surgery, hospitalization, and lengthy recovery time, with corresponding impact on the patient's quality of life and even fatality [6]. The local effect of complications can reduce the viability of the augmentation and, hence, that of the inserted implants. The most common complication is perforation of the Schneiderian membrane, which however does not show any connection to postoperative complications. Approximately $15 \%$ develops postoperative complications, including wound infection, abscess, or dehiscence with drainage, partial exposure of the simultaneous onlay graft, loss of the graft and trancient maxillary sinusitis [7]. Previous investigations have reported maxillary sinusitis up to $20 \%$ of patients after sinus lift procedures (SLP) [8]. The purpose of this article is to present a patient with a chronic sinusitis after two SLPs and multiple implantations in the maxilla.

\section{Case Report}

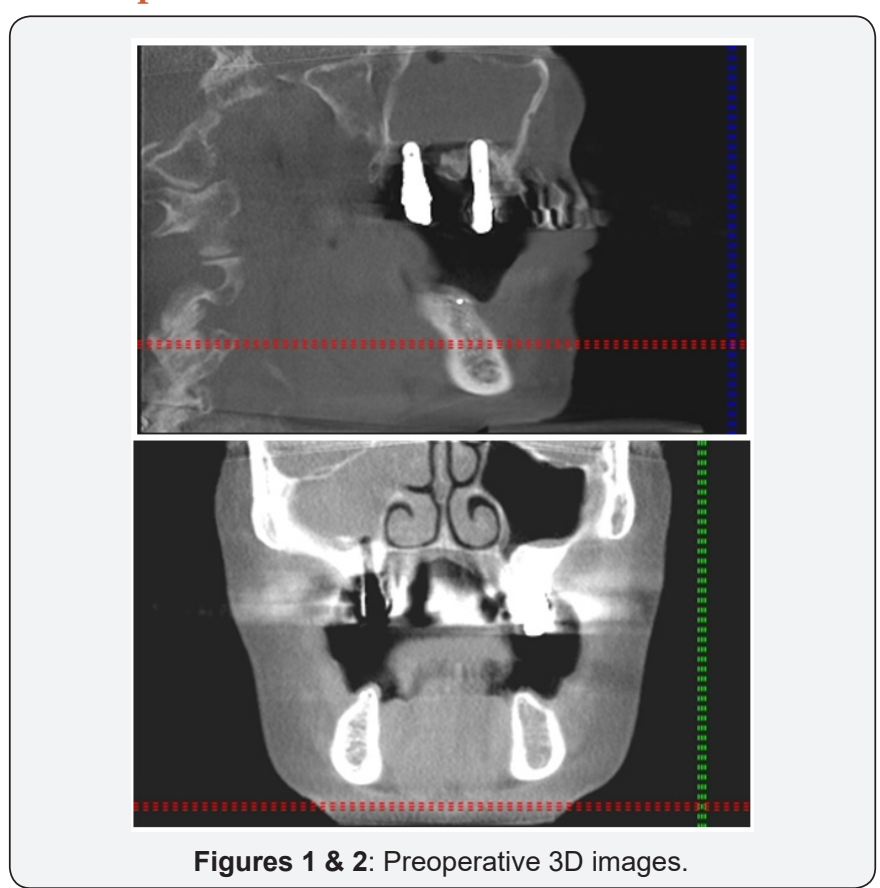




\section{Global Journal of Otolaryngology}

A 60-years old female patient referred to our Clinic with an oroantral fistula on the right side after SLP and implantation in 2008. From the anamnesis there was reported a late implantation in 2003 alio loco with external sinus lift after trauma related to a bicycle accident in 1980. Between the accident and the first implantation the patient was treated with crowns and bridges. After two years of severe facial pain she applied for removal of the implant. In 2008 free of pain underwent a second implantation. Since the operation mentioned increased facial pain localized at the operated side (Figures $1 \& 2$ ).

The clinical Examination showed except the severe pain in the region of 15 and the oroantral fistula with drain of pus, no evidence of an acute sinusitis. The peirimplant probing depth measurements revealed a severe periimplantitis with immediate connection to the sinus floor. Additionally the implants 17 and 27 showed an untreatable periimplantitis with bone loss of $5 \mathrm{~mm}$. According to the performed trigeminal tests was no evidence of trigeminal neuralgia. The 3D radiology examination without contrast revealed an opaque appearance, capturing the whole right maxillary sinus. The Patient had a medical history of Hashimoto-thyroiditis and TIA.

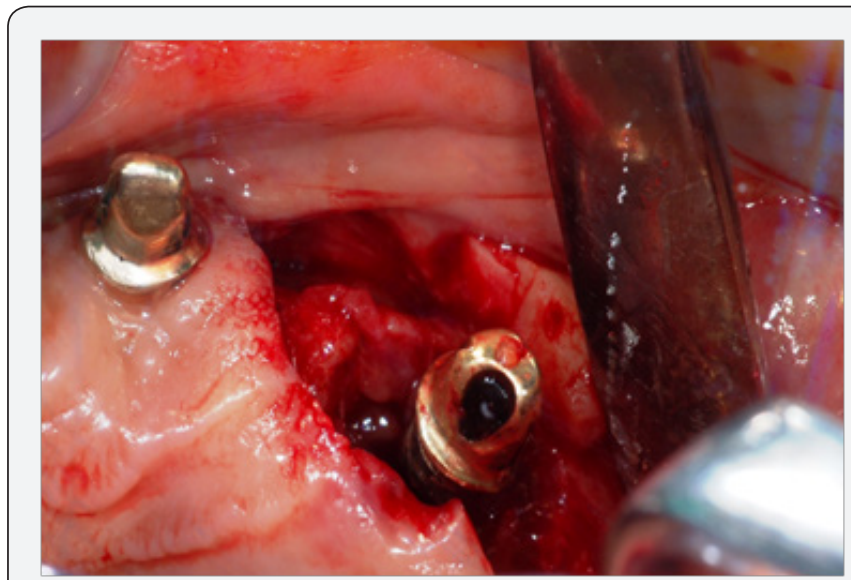

Figures 3: Periimplantitis 15 with massive bone loss.

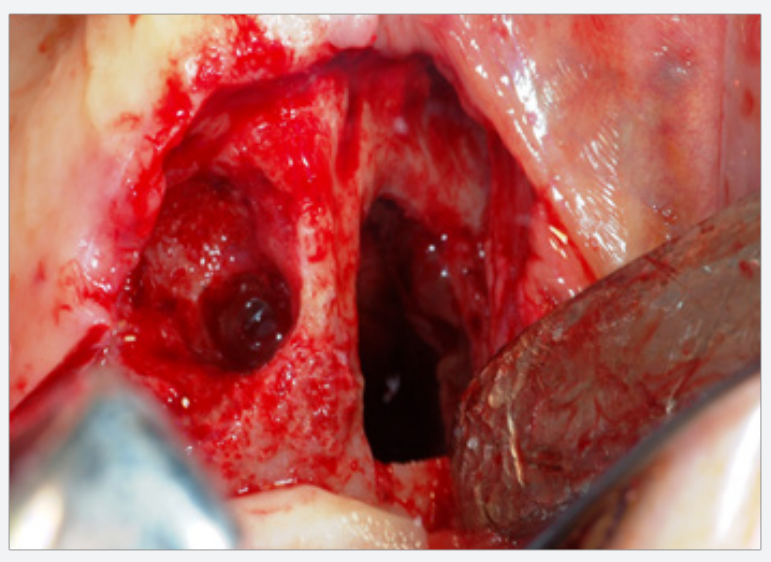

Figures 4: Oro-antral fistel after explantation.
After a one-day treatment with intravenous Ambicillin 2g/ sulbactam 1g every 8 hours per day, the patient was leaded to an open sinus revision surgery with explantation of 15,17 and 27 under general anesthesia. The granulations tissue of the right maxillary sinus was completely excised and after endoscopic revealing of dislocation of Osteum, a naso-antral window for aeration and drainage of the sinus was decided. The postoperative images confirmed the complete excision of the inflamed tissue. The microbiology report showed numerous grampositive coccus and gramnegative anaerobs, compatible to a chronic sinusitis according to the international literature [9]. The histology report revealed a chronic infection with B-Lymphocytes and eosinophils, compatible to a chronic sinusitis as well [10].

The patient recovered completely after a 3-day hospital stay and discharged with antibiotics (Amoxicillin/clavulanate $875 / 125 \mathrm{mg}, 2$ times daily), continued for 10 days in combination with a nasal decongestant (Xylometasolin 0,1\%, 4 times per day). The signs of sinusitis were reduced after medical treatment and the pain had ceased. No recurrence of symptoms was reported at long-term follow-up examination, 1 year after surgery (Figures 3-9).

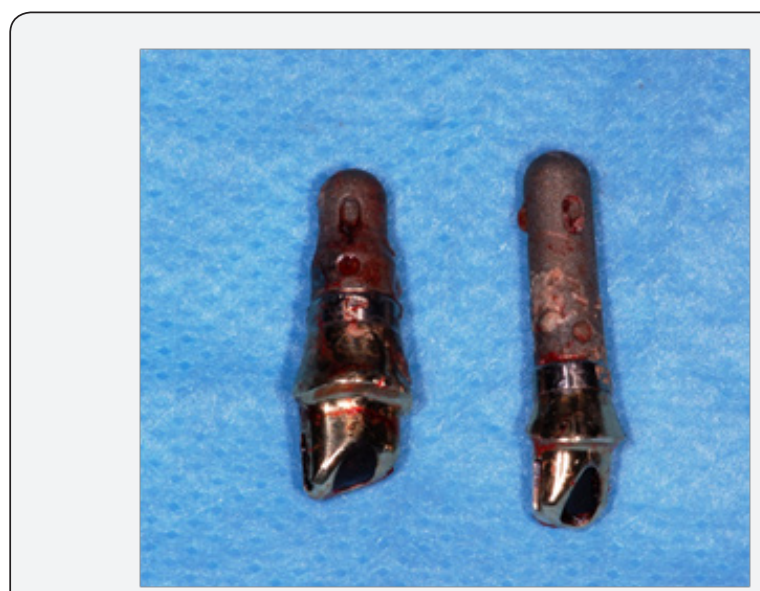

Figures 5: Implants 15,17 after explantation.

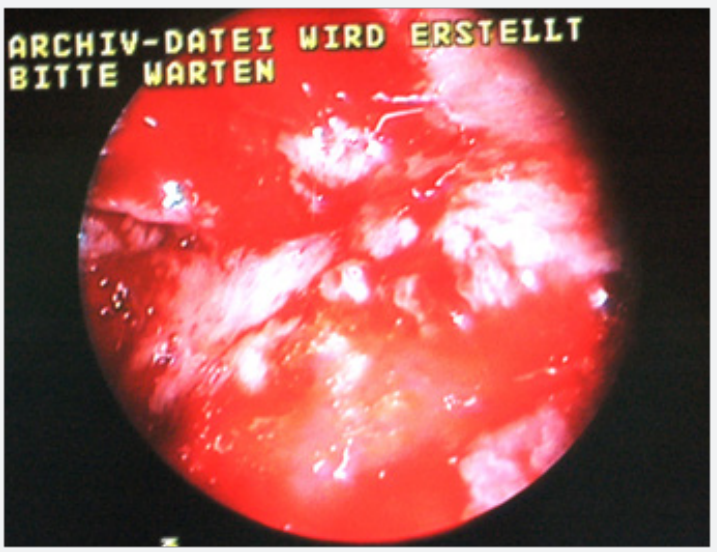

Figures 6: Endoscopy with constipation of ostium. 


\section{Global Journal of Otolaryngology}
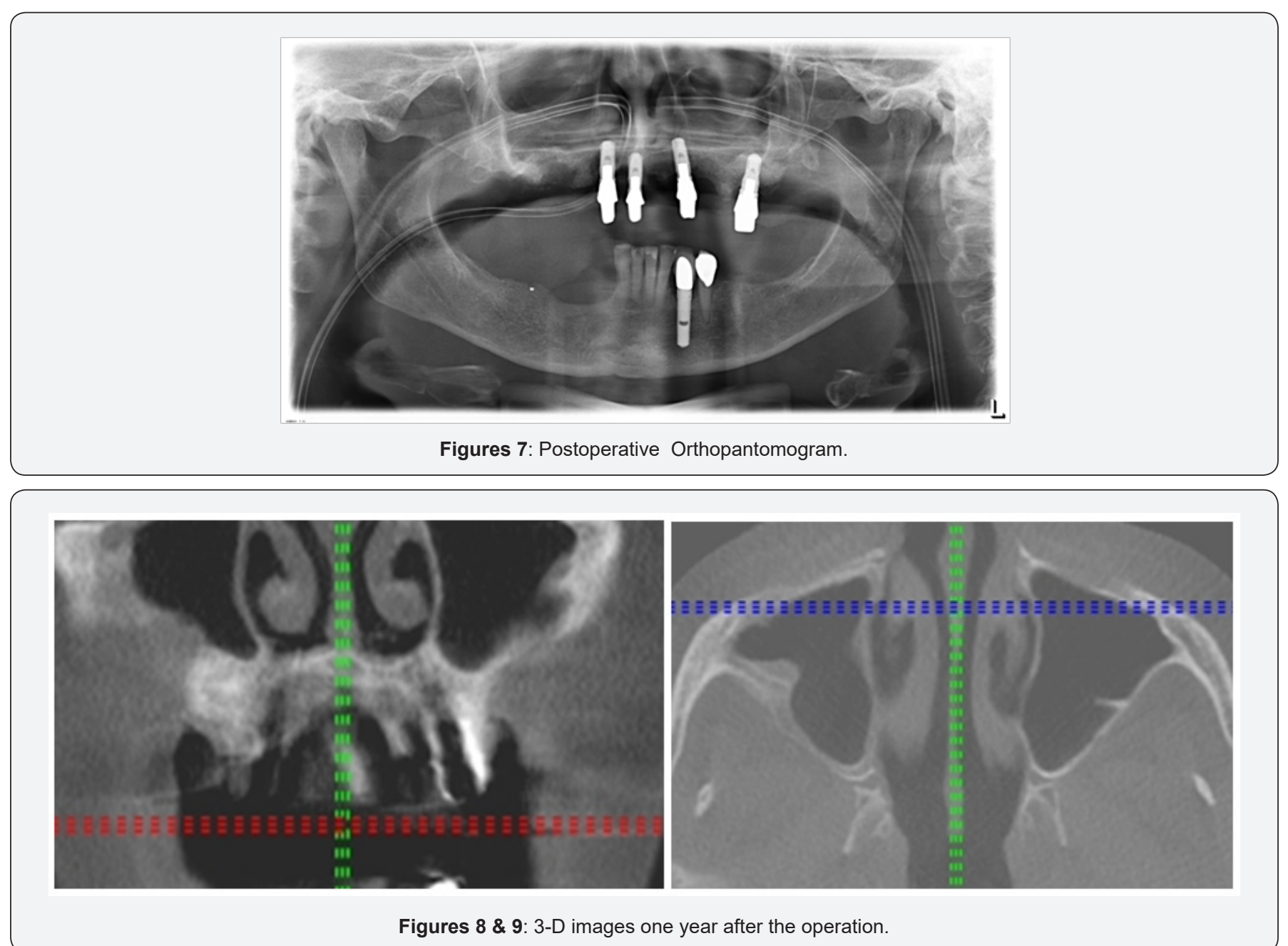

Discussion

Sinus lift procedure is a quite reliable technique for augmentation the atrophic maxilla. However a perforation of the Schneiderian membrane when is combined with a displayment of the implant can be episodically associated to oroantral fistulae and sinusitis [11]. The most common mechanism of infection after Sinus lift supports that the obstruction of the physiological drainage through the reaction of the mucosa to a foreign body can cause Rhinosinusitis [12]. The edema of ostiomeatal complex reduces the aeration of sinus giving rise to mutation of normal flora to anaerobic. The established infection can create then a vicious circle by enlargement of edema, less aeration and more severe infection [13].

In the various experimental models is not yet defined in which grade the extension of the implants or alloplastic material into the sinus can cause an inflammatory reaction. It is observed that exposion of implants in the sinus for less than $2 \mathrm{~mm}$ is covered spontaneously from healing mucosa [13]. The cover of the foreign bodies by normal mucosa can generally lead to a normal wound healing with good prognosis [14]. Controversially by placement of zygomatic implants there are immense areas of foreign material remain uncovered without rising infection to the sinus.

The proposed therapy option for a rhinosinusitis caused by foreign body reaction is the surgical revision of the sinus but with the necessity of implant removal remaining still controversial $[15,16]$. The most indicated technique for the revision is FESS (Functional Endoscopic Sinus Surgery), which is favored over Caldwell-Luc because, is less invasive offering same results. In our case through a severe periimplantitis with chronic pain and infection of the whole maxillary sinus we decided to perform a more radical surgery, including the removal of the located implants in the regions 15 and 17 for avoiding a relapse.

\section{Conclusion}

Although sinus lift procedures considered to be safe methods for maxilla augmentation and perforation of Schneiderian membrane, with the appropriate treatment [17], has not be proved to be a determining factor for sinusitis, there is an impending need for conducting randomized controlled clinical trials to test the interaction between sinus mucosa and foreign body. In conclusion, the existing types of therapy should always 
be related and modified according to the situation. The presented concept of therapy provides a secure method of treating patients with multiple recurrent sinusitis.

\section{References}

1. Boyne PJ, James RA (1980) Grafting of the maxillary sinus floor with autogenous marrow and bone. J Oral Surg 38(8): 613-616.

2. Breine U, Branemark PI (1980) Reconstruction of alveolar jaw bone. An experimental and clinical study of immediate and preformed autologous bone grafts in combination with osseointegrated implants. Scand J Plast Reconstr Surg 14(1): 23-48.

3. Tatum H (1986) Maxillary and sinus implant reconstruction. Dent Clin North Am 30(2): 207-229.

4. Wheeler SL, Holmes RE, Calhoun CJ (1996) Six-Year Clinical and Histologic Study of Sinus-Lift. Int J Oral Maxillofac Implants 11(1): 2634.

5. Herzberg R, Dolev E, Schwartz-Arad D (2006) Implant marginal bone loss in maxillary sinus grafts. Int J Oral Maxillofac Implants 21(1):103110.

6. Manor Y, Mardinger O, Bietlitum I, Nashef A, Nissan J, et al. (2008) Late signs and symptoms of maxillary sinusitis after sinus augmentation. Oral Surg Oral Med Oral Pathol Oral Radiol Endod 110(1): 1-4.

7. Moreno Vazquez JC, Gonzalez de Rivera AC, Serrano Gil H, Mifsut RS (2014) Complication Rate in 200 Consecutive Sinus Lift Procedures: Guidelines for Prevention and Treatment. 2014 American Association of Oral and Maxillofacial Surgeons. J Oral Maxillofac Surg 72(5): 892901

8. Timmenga NM, Raghoebar GM, Boering G, van Weissenbruch R (1997) Maxillary sinus function after sinus lifts for the insertion of dental implants. J Oral Maxillofac Surg 55(9): 936-939.

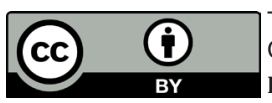

This work is licensed under Creative Commons Attribution 4.0 License DOI: $10.19080 /$ GJO.2017.04.555650
9. Brook I (2006) Bacteriology of Chronic Sinusitis and Acute Exacerbation of Chronic Sinusitis. Arch Otolaryngol Head Neck Surg 132(10): 1099-1101.

10. Malekzadeh S, McGuire JF (2003) The New Histologic Classification of Chronic Rhinosinusitis. Curr Allergy Asthma Rep 3(3): 221-226.

11. Chiapasco M, Felisati G, Maccari A, Borloni R, Gatti F, et al: The management ofcomplications following displacement of oral implants in theparanasal sinuses: a multicenter clinical report and proposedtreatment protocols. Int J Oral Maxillofac Surg 38(12): 12731278.

12. Pignataro L, Mantovani M, Torretta S, Felisati G, Sambataro G (2008) ENT assessment in the integrated management of candidate for (maxillary) sinus lift. Acta Otorhinolaryngol Ital 28(3): 110-119.

13. Jung JH, Choi BH, Jeong SM, Li J, Lee SH, et al. (2007) A retrospective study of the effects on sinus complications of exposing dental implants to the maxillary sinus cavity. Oral Surg Oral Med Oral Pathol Oral Radiol Endod 103(5): 623-625.

14. Brånemark PI, Adell R, Albrektsson T, Lekholm U, Lindström J, et al. (1984) An experimental and clinical study of osseointegrated implants penetrating the nasal cavity and maxillary sinus. J Oral Maxillofac Surg 42(8): 497-505.

15. Chen YW, Huang CC, Chang PH, Chen CW, Wu CC, et al. (2013) The characteristics and new treatment paradigm of dental implant-related chronic rhinosinusitis. Am J Rhinol Allergy 27(3): 237-244.

16. Chiapasco M, Felisati G, Zaniboni M, Pipolo C, Borloni R, et al. (2013) Thetratment of sinusitis following maxillary sinus grafting with the association of functional endoscopic sinus surgery (FESS) and an intra-oral approach. Clin Oral Implants Res 24(6): 623-629.

17. Becker ST, Terheyden H, Steinriede A, Behrens E, Springer I, et al. (2008) Prospective observation of 41 perforations of the Schneiderian membrane during sinus floor elevation. Clin Oral Impl Res 19(12): $1285-1289$

\section{Your next submission with Juniper Publishers will reach you the below assets}

- Quality Editorial service

- Swift Peer Review

- Reprints availability

- E-prints Service

- Manuscript Podcast for convenient understanding

- Global attainment for your research

- Manuscript accessibility in different formats

( Pdf, E-pub, Full Text, Audio)

- Unceasing customer service

Track the below URL for one-step submission

https://juniperpublishers.com/online-submission.php 